\title{
PREVALENCE OF TUBERCULOSIS AMONG HIV POSITIVE PATIENTS ATTENDING ICTC IN A TERTIARY CARE INSTITUTE IN AHMADABAD, A WESTERN CITY OF INDIA
}

\author{
Nayak S', Karia J2, Patel P3 , Modi B', Desai K4, Patel B \\ 1,4,5 Department of Community Medicine, Surat Municipal Institute of Medical Education and Research \\ (SMIMER), Surat, Gujarat, India \\ 2,3 Department of Microbiology, GMRES Medical College, Sola, Ahmadabad, Gujarat, India
}

\begin{abstract}
Introduction: In India, tuberculosis is the most common opportunistic infection among HIV positive patients. This study estimates the prevalence of tuberculosis amongst HIV patients in Ahmadabad, Gujarat.
\end{abstract}

Methodology: The present study was conducted at Integrated Counseling and Testing Center for HIV at Sola civil hospital, a public sector tertiary care hospital in Ahmadabad for a twenty month period from January, 2009 to August, 2010. All the patients visiting the center during the study period were screened for HIV. All the patients who were diagnosed HIV positive were subjected for active search of tuberculosis; clinically, radiological as well as by histopathology and laboratory tests.

Results: Total 6846 patients were screened for HIV, out of which 167(2.44\%) patients were tested HIV positive. Out of 167 HIV positive patients, 22 (13.17\%) were diagnosed as cases of tuberculosis. Out of these 22 patients, $18(81.82 \%)$ had pulmonary tuberculosis while $4(18.18 \%)$ were extra-pulmonary tuberculosis patients. Amongst the four extra-pulmonary tuberculosis cases, one $(25.00 \%)$ case was of tuberculous meningitis, one (25.00\%) was of abdominal tuberculosis and two $(50.00 \%)$ had tuberculous lymphatic swelling.

Conclusion: The prevalence of tuberculosis in HIV positive patients found in this study was $13.17 \%$, which is substantially lower than that reported in previous studies. Appropriate management of these patients requires a strengthened mechanism of cross reference and inter sectoral co-ordination between the two diseases at all levels.

Key words: HIVIAIDS, Tuberculosis, Prevalence

\section{INTRODUCTION}

Tuberculosis, though an ancient disease, continues to remain a major public health problem in much of the developing world even today. Worldwide it is the most prevalent infectious cause of human suffering and death. ${ }^{1}$ The problem is now further complicated

\footnotetext{
Correspondence:

Dr. Sunil Nayak

Associate Professor, Community Medicine Department GMERS Medical College, Dharpur,

Patan, Gujrat, India

Email: drsunilnayak@gmail.com
}

by relentless spread of HIV and associated AIDS pandemic. HIV infection aggravates the progression to active disease in people infected with tuberculosis (TB). HIV infected individuals co-infected with TB bacilli have an annual risk of $5-15 \%$ of developing active TB. ${ }^{2}$ In India, TB is the most common opportunistic infection among HIV sero-positive patients. ${ }^{3}$ Currently in India 2.5 million people are infected with HIV of whom $40 \%$ are co-infected with TB.,5 HIV-TB co-infection represents a deadly combination. The co-infection is associated with various factors like malnutrition, unemployment, alcoholism, drug abuse, poverty, homelessness and illiteracy. ${ }^{6}$ 
Further, appropriate management of patients with TB-HIV requires not only treating the TB and HIV alone but a strengthened mechanism of cross reference between the Anti-retroviral treatment (ART) centre and Directly Observed Treatment Short Course (DOTS) centre wherever indicated. If HIV prevalence in the community continues to increase, it could affect the TB control program, by decreasing cure rates and increasing mortality and recurrent TB.

So the present study was planned with the objective of estimating the prevalence of TB in HIV positive patients attending Integrated Counseling and Testing Center (ICTC) for HIV of a tertiary care public hospital at Ahmadabad, India.

\section{METHODOLOGY}

Study design: This is a cross-sectional study.

Study setting:_The study was conducted in ICTC centre of tertiary care public hospital in Sola, Ahmadabad, Gujarat, India.

Study period: January, 2009 to August, 2010

Sampling: All patients $(n=6846)$ attending ICTC centre during the study period were included in the study.

Data collection: All patients attending ICTC in the study period were initially screened for HIV testing by various spot kits like Immunocomb, Tridot, SD HIV rapid test as per the National AIDS Control Programme (NACP) guidelines. Those who were found to be positive were rechecked by Enzyme Linked Immunosorbent Assay (ELISA) test before sending samples as a positive. An active search for TB disease was made in all HIV positive cases based on combined results of clinical, radiological, histo-pathological and laboratory investigations in accordance with protocol established by Revised National Tuberculosis Control Program (RNTCP).

Patient was diagnosed as a case of Pulmonary TB as per RNTCP protocol if

1) Either sputum smears (sputum acid-fast bacilli) positive 'OR'

2) Sputum smears negative but meeting all three of the following clinical criteria

a. Symptoms suggestive of TB

b. Chest X - Ray (Posterior-Anterior view) suggestive of TB

\section{c. A positive anti - TB treatment response}

Diagnosed of extra-pulmonary TB case as well determination of the focus of it was based on clinician's final judgment. This in turn was based on clinical examination as well as routine investigations like Hemoglobin $(\mathrm{Hb})$, Total Lymphocyte counts (TLC), Differential Lymphocyte count (DLC), Erythrocyte Sedimentation Rate (ESR), urine (albumin, sugar and microscopic examination) performed in all cases. Other investigations like Fine Needle Aspiration Cytology (FNAC) of enlarged lymph nodes, abdominal ultrasongrophy (USG) and lumber puncture were also performed on case to case basis as per the clinician's advice.

Ethics: The study was approved by the Institutional Ethical Committee (IEC) of Sola medical college. Informed consent was taken from all participants before testing. Pre-test counseling was also assured in all participants. Patients diagnosed with TB were started on Anti-TB Treatment (ATT) and were subjected to clinical and laboratory monitoring on a periodic basis and also at the conclusion of ATT from ethical point of view.

Data analysis: Data entry was done followed by data analysis using Epi Info 2007. Descriptive analysis with frequency distribution of patients for different variables was carried out.

\section{RESULTS}

Total 6846 patients were screen for HIV during a study period of 20 months, out of this $167(2.44 \%)$ patients were found HIV positive. All 167 patients were screened for TB. Out of them (167), 22 $(13.17 \%)$ were diagnosed TB positive and 145(86.83\%) were TB negative (Table 1).

Table 1 shows that out of total 22 TB patients among HIV patients, $18(81.82 \%)$ had pulmonary TB while $4(18.18 \%)$ were extra-pulmonary TB patients. Out of 18 pulmonary TB, $12(66.67 \%$ ) were detected by sputum examination with Zeil Nelson (ZN) staining and $6(33.33 \%)$ were detected by X-Ray chest findings. Amongst four extra-pulmonary TB cases, one $(25.00 \%)$ case was of TB meningitis, one $(25.00 \%)$ was of abdominal TB and two (50.00\%) were of TB lymphatic swelling. 


\begin{tabular}{|l|l|l|l|l|}
\hline \multicolumn{4}{|l|}{ Table 1. Distribution of tuberculosis among HIV positive patients } \\
\hline Amongst HIV positive patients( $\mathrm{n}=167)$ & $\begin{array}{l}\text { Total HIV } \\
\text { positive }\end{array}$ & Total patients screened \\
\hline Tuberculosis positive & Tuberculosis negative & $145(86.83 \%)$ & $167(2.44 \%)$ & $6846(100 \%)$ \\
\hline $22(13.17 \%)$ & \multicolumn{3}{|l|}{ Extra-pulmonary tuberculosis } \\
\hline Amongst Tuberculosis positive patients ( $\mathrm{n}=22)$ & $4(18.18 \%)$ \\
\hline \multicolumn{4}{|l|}{ Pulmonary tuberculosis } & Amongst extra-pulmonary tuberculosis patients $(\mathrm{n}=4)$ \\
\hline $18(81.82 \%)$ & $\begin{array}{l}\text { Tuberculosis } \\
\text { meningitis }\end{array}$ & $\begin{array}{l}\text { Abdominal } \\
\text { tuberculosis }\end{array}$ & $\begin{array}{l}\text { Tuberculous } \\
\text { lymphatic swelling }\end{array}$ \\
\hline Amongst pulmonary tuberculosis patients $(\mathrm{n}=18)$ & $\begin{array}{l}\text { Diagnosed by } \\
\text { chest X-ray }\end{array}$ & $1(25.00 \%)$ & $1(25.00 \%)$ & $2(50.00 \%)$ \\
\hline Diagnosed by Ziehl-Neelsen stain $)$
\end{tabular}

Out of total 167 HIV positive patients, $108(64.67 \%)$ were males and 59(35.33\%) were females. Maximum number of HIV positive patients $69(41.32 \%)$ were from 25 to 34 years of age (43(25.75\%) males and $26(15.57 \%)$ females). After that $62(37.13 \%)$ of patients were from 35 to 49 years of age $(41(24.55 \%)$ males and $21(12.57 \%)$ females.

Our study shows maximum number of TB patients 9(40.91\%) among HIV positives were also from 25 to 34 years of age group. After that $8(36.36 \%)$ of patients were from age group of 35 to 49 years. Only $2(9.09 \%)$ of patients were less than 14 years of age.

Among TB patients, 16(72.73\%) patients were males and $6(27.27 \%)$ were females.

\section{DISCUSSION}

The prevalence of TB amongst HIV positive patients at ICTC was $13.17 \%$ in present study. Another Madras bases prospective study by Solomon $S$ et al in $1995(n=1430)$ on trends on HIV infection in Pulmonary TB showed the co-infection prevalence to be $3.4 \%{ }^{7}$ Ghate MV et al from Pune in his crosssectional studies conducted consecutively for three years have shown the prevalence of TB in HIV infection to be $11.8 \%, 9.94 \%$ and $7.4 \%$ in the year 1997, 1998, 1999 respectively $(n=3574) .^{8}$ While in contrast to this one Lucknow based cross-sectional study by Sircar AR et al in $1998(n=74)$ showed the same prevalence to be quite high, that is $54.8 \%{ }^{9}$ Kumar P et al, 2002 from Delhi showed that the prevalence of Acid Fast Bacilli (AFB) positive sputum amongst HIV patients is $21.4 \%$, while the prevalence of extra pulmonary TB infection is almost double that is $45.6 \% \quad(n=306) . .^{10}$ Similarly the prevalence of Multi drug resistant (MDR) TB amongst HIV infected persons was found to be $4.42 \%$ by a Chennai based investigator in 2002 in a cross-sectional study conducted on 1000 patients. ${ }^{11}$ A case control study $(n=1009)$ conducted in Mumbai by Hira SK et al $(n=1009)$ have shown the prevalence of TB amongst HIV cases is $25.4 \% .{ }^{12}$ Where as a Calcutta based cross-sectional study have shown the same prevalence of TB among HIV patients to be $27.7 \% .{ }^{13}$ Likewise a study on Bone TB prevalence amongst HIV patients have found the prevalence of the same to be around 40\% ( $n=140) .{ }^{14}$ Mahajan A et al from Jammu has shown the prevalence of HIV-TB co-infection of $16.52 \% .^{15}$

Thus it is evident from above evidences that there is wide regional variation in the prevalence of HIVTB co-infections in India and hence findings of one region cannot be extrapolated to other regions without a proper study. Though difference in the strengths of study designs, sample size and study period (prospective studies superior than crosssectional) as well as center to center diagnostic capabilities especially for extra pulmonary TB and lack of standard to compare for the same might also be responsible for these huge variations.

There are also many studies from out of India showing different rate of HIV prevalence, indicating even a huge inter country variation in addition to the intra country variation for the same. Like a review study from Netherlands in 90's $(n=13269)$ has shown the prevalence of HIV amongst TB patients to be around $4 \%{ }^{16}$, while a study from 
Ukrain has shown the prevalence of co-infection to be $6.3 \%$ and $10.1 \%$ respectively in 2002 $(n=567)$ and $2004(n=968)$ respectively ${ }^{17}$, where as a hospital based review study from Nigeria has shown the same prevalence to be around $28.12 \%$ $(n=777)^{18}$, which is again in contrast to another Uganda based retrospective evaluation $(n=6305)$ of $5 \%{ }^{19}$, and Atlanta, USA based cross-sectional evaluation $(n=272)$ of $1 \%$ sero-prevalence among TB patients. ${ }^{20}$

To promote early diagnosis and treatment of TB in HIV infected individuals and vice versa, at the national level, there is a concerted effort to achieve coordination between the designated microscopy centre (DMC) of the RNTCP and the ICTC of the HIVIAIDS control program not only to improve the outcome of HIV-infected TB patients but also to control the burden of tuberculosis in India ${ }^{21}$. As a part of this all ICTC clients with suggestive symptoms are referred by the counselor to the nearest microscopy centre for investigations to rule out TB. ${ }^{21}$ In 2007, approximately $5 \%$ of all diagnosed TB cases in India came from ICTCs. ${ }^{21}$

Our study shows pulmonary involvement in $81.82 \%$ of cases which is almost equal to results of Deivanayagam et al, 2001 and Ahmad and Shameem,2005 which shows pulmonary involvement of about $75 \%$ of all HIV infected patients with TB. ${ }^{22,23}$ TB-HIV co-infection is already a well recognized public health problem particularly in developing countries. ${ }^{1,9,10}$ HIV infection is the most potent factor in transforming latent or recently acquired TB infection to active clinical disease. ${ }^{24,25}$

Extra-pulmonary TB is the commonest cause of pyrexia of unknown origin (PUO) among HIV positive individuals in developing countries and is more common among people with advanced HIV disease. 26,27 The most frequent extra-pulmonary form of TB is involvement of the lymph nodes with cervical region being the commonest. ${ }^{28}$ The other forms of extra-pulmonary TB include pleural effusion, pericardial effusion, abdominal TB, TB meningitis and abdominal TB. ${ }^{21}$ In current study $4(18.18 \%)$ were extra-pulmonary TB patients with two of them having tuberculous lymphatic swelling, one having abdominal TB and one case of TB meningitis. Another study by Mansoori et al showed $80.9 \%$ cases of smear-positive pulmonary
TB, $10.9 \%$ of smear-negative pulmonary TB; and $8.2 \%$ of extra-pulmonary TB which consisted of 3 cases of TB lymphadenitis, one pleural TB case, one case of TB meningitis, and one liver TB case..$^{29}$

Patients with HIV co-infection may not have typical radiographic features of pulmonary tuberculosis on chest X-ray and it may be normal in $5-10 \%$ of individuals. ${ }^{30}$ While patients with higher CD4 cells (>350 cells $/ \mathrm{mm}^{3}$ ) have radiographic abnormalities similar to their HIV negative counterparts, patients with immunosuppression often have minimal or atypical findings which includes diffuse pulmonary infiltrates/opacities dominantly and uncommonly cavitation. ${ }^{31}$ Miliary pattern, mediastinal adenopathy and pleural effusion are also more common. ${ }^{30}$ In current study out of total diagnoses pulmonary TB cases $33.33 \%$ were diagnosed by chest $x$-ray.

Our study shows that out of total HIV positive patients, $35.33 \%$ were females, which is almost equal to National AIDS Control Organization (NACO) report 2007 showing that among all HIV positive patients $31.2 \%$ are females. ${ }^{32}$ Yadav DK et al showed the proportion of females amongst the HIV positives of $24.8 \% .^{33}$

Our study reveal that maximum number of HIV positive patients $69(41.32 \%)$ were from 25 to 34 years of age. Yadav DK et al revealed that majority of HIV positive subjects are in the age group of 3039 years $(48.8 \%) .{ }^{33}$

Our study shows that maximum number (40.90\%) of TB-HIV co-infected positive patients were from 25 to 34 years of age group. After that $36.36 \%$ of patients were from age group of 35 to 49 years. These results are almost equal to Bernard J Ngowi et al's findings which shows the same prevalence as $45.0 \%$ and $30.0 \%$ in the age group of 25 to 34 years and 35 to 49 years respectively. ${ }^{34}$ Yadav DK et al revealed that $60 \%$ of TB/HIV co-infected belonged to the age group (31-40) years, while $35.7 \%$ of subjects was belonged to age group (2130 ) years. ${ }^{33}$ Mansoori $D$ et al revealed that $64 \%$ of TB/ HIV infected patients were 20-40 years old and $36 \%$ were 41 years old or more. ${ }^{29}$

Limitation:

It is possible that some under diagnosis, especially of extra-pulmonary TB as well as sub clinical 
infections did occurred, as our diagnostic methods were restricted to sputum smears, radiographs, clinical judgment and routine laboratory tests. Other investigations like USG, FNAC was done only in symptom suggestive patients based on clinician's advice.

\section{CONCLUSION}

In this study 22(13.17\%) subjects were patients with HIV-TB dual disease, most of whom were pulmonary TB cases. This prevalence is substantially lower than that reported in previous studies indicating regional variations in the prevalence of the same.

Further appropriate management of these patients requires a strengthened mechanism of cross reference and inter sectoral coordination between the two diseases at all levels which requires further operational research. One of the programmatic limitations encountered in this is the lack of investigations for extra-pulmonary TB at peripheral health facilities.

\section{REFERENCES}

1. Zumla A, Malon P, Henderson J. Impact of HIV infection on Tuberculosis. JAMA 2001;4:33-40.

2. Ellzabeth LC, Walt CJ, Walker N. The growing burden of Tuberculosis. Arch Intern Med 2003;163:1009-21.

3. Swaminathan S, Ramachandran R, Baskeran G, Paramasivan $\mathrm{CN}$, Ramanathan $\mathrm{U}$, Venkatesan $\mathrm{P}$, et al. Development of Tuberculosis in HIV infected individuals in India. Int J Tubers Lung Dis 2000;4:839-44.

4. Marfatia YSSA, Modi M. Overview of HIVIAIDS in India. J Sex Transmission Disease 2007;28:1-5.

5. Sharma SK. Co-infection of HIV and TB Indian perspective. Indian J Tuberculosis 2004;51:5-16.

6. Tillekratne LG, Kiwera RA, Cha HY, Kaale L, Morpeth SC, Ostermann J, et al. Morbidity and mortality among a cohort HIV - infected adults in a programme for community home based care in the Kilimanjaro Region of Tanzania (2003-2005). Ann Trop Med Parasitology 2009;103:263-73.

7. Solomon S, Anuradha S, Rajasekaran S. Trend of HIV infection in patients with pulmonary Tuberculosis in South India. Tuber Lung Dis 1995;76:17-9.
8. Ghate MV, Divekar AD, Risbud AR. Thakar MR, Brahme RG, Mehendale SM. Changing trends in clinical presentations in referred Human Immunodeficiency Virus infected persons in Pune, India. JAPI 2002;50:671-3.

9. Sircar AR, Tripathi AK, Choudhary SK, Misra R. Clinical profile ofAIDS:A study at a referral hospital. JAPI 1998;46:775-8.

10. Kumar P, Sharma N, Sharma NC, Patnaik S. Clinical profile of Tuberculosis in patients with HIV Infection/AIDS. Ind J Chest Dis Allied Sci 2002;44:159-63.

11. Deivanayagam $C N$, Rajasekaran $S$, Venkatesan $R$, Mahilmaran A, Ahmed PR, Annadurai S, et al.. Prevalence of acquired MDR-TB and HIV co-infection. Ind J Chest Dis Allied Sci 2002;4 4:237-42.

12. Hira SK, Shroff HJ, Lanjewar DN, Dholkia YN, Bhatia VP, Dupont HL. The natural history of Human Immunodeficiency Virus infection among adults in Mumbai. Nat Med J Ind 2003;16:126-31.

13. Dey SK, Pal NK, Chakrabarty MS. Cases of Human Immunodeficiency Virus infection and Tuberculosis - Early experiences of different aspects. J Ind Med Assoc 2003;101:291-2.

14. Khandekar MM, Deshmukh SD, Holla VV, Rane SR, Kakrani AL, Sangale SA, et al. Profile of bone marrow examination in HIVIAIDS patients to detect opportunistic infections, especially Tuberculosis. Ind J Pathol Microbial 2005;48:7-12.

15. Mahajan A, Tandon V, Verma S, et al. HIVIAIDS \& Coinfections. Paper presented in IACMCON, 14thAnnualConference at HIMS, Dehradun 2006.

16. Haar $\mathrm{CH}$, Cobelens FG, Kalisvaart NA, Van der Have JJ, Van Gerven PJ, Van Deutekom H. HIV prevalence among Tuberculosis patients in The Netherlands, 1993-2001: Trends and risk factors. Int J Tuberc Lung Dis 2006;10:768-74.

17. Vander Werf MJ, Yegorova OB, Chentsova $\mathrm{N}$, Chechulin $\mathrm{Y}$, Hasker E, Petrenko V, et al. Tuberculosis-HIV Co-infection in Kiev City, Ukraine. Emerg Infect Dis 2006;12:766-8.

18. Ige OM, Sogaolu OM, Ogunlade OA. Pattern of presentation of Tuberculosis and the hospital prevalence of Tuberculosis and HIV co-infection in University College Hospital, Ibadan: A review of five years (1998-2002). Afr J Med Med Sci 2005;34:32933.

19. Mugisha B, Bock N, Mermin J, Odeke RM, Miller B, Adatu-Engwau F, et al. Tuberculosis case finding and preventive therapy in an HIV voluntary counseling and testing center in Uganda. Int J Tuberc Lung Dis 2006;10:761-7. 
20. Richards DC, Mikiashvili T, Parris JJ, Kourbatova EV, Wilson JC, Shubladze N, et al. High prevalence of Hepatitis $C$ virus but not HIV co-infection among patients with Tuberculosis in Georgia. Int J Tuberc Lung Dis 2006;10:396-401.

21. Swaminathan S, Narendran G. HIV and tuberculosis in India. J Biosci 2008;33:527-37.

22. Deivanayagam $\mathrm{CN}$, Rajasekaran $\mathrm{S}$, Senthilnathan V, Krishnarajasekhar R, Raja $\mathrm{K}$, Chandrasekar $\mathrm{C}$, et al. Clinicoradiological spectrum of tuberculosis among HIV seropositives - A Tambaram study. Ind J Tuber 2001;48:123-7.

23. Ahmad Z, Shameem M. Manifestations of Tuberculosis in HIV Infected Patients. JIACM 2005; 6:302-5.

24. Meya DB, McAdam KP. The TB pandemic, an old problem seeking new solutions. Journal of Internal Medicine 2007;261:309-29.

25. Giradi E, Raviglione MC, Antonucci G, Godfrey - Fausseft P, Ippolito G. Impact of the HIV epidemic on the spread of other diseases: The case of Tuberculosis. AIDS 2000;14:47-56.

26. Rupali $P$, Abraham OC, Zachariah A, Subramanian S, Mathai D. Aetiology of prolonged fever in antiretroviral-naïve human immunodeficiency virus-infected adults. Natl Med J India 2003;16:193-9.

27. Kejariwal D, Sarkar N, Chakraborti SK, Agarwal V, Roy S. Pyrexia of unknown origin: a prospective study of 100 cases. J Postgrad Med 2001;47:104-7.
28. Arora VK, Kumar SV. Pattern of opportunistic pulmonary infections in HIV sero-positive subjects: observations from Pondicherry, India. Indian J Chest Dis Allied Sci 1999;41:135-44.

29. Mansoori D, Alaei K, Alaei A. Prevalence of Clinical Tuberculosis in HIV Infected Patients from Kermanshah Province, IRAN. Tanaffos 2002;1:27-33.

30. Swaminathan $S$, Narendran G, Menon PA, Padmapriyadarsini C, Arunkumar N, Sudharshanam NM, et al. Impact of HIV infection on radiographic features in patients with pulmonary tuberculosis. Indian J Chest Dis Allied Sci 2007;49:133-6.

31. Long R, Maycher B, Scalcini M, Manfred J. Chest roentgenogram in pulmonary tuberculosis patients seropositive for HIV type I. Chest 1999; 99:123-7.

32. National AIDS control Organization. NACO Annual Report 2007. NACO: New Delhi; 2007.

33. Yadav DK, Jha N, Pokharel PK, Niraula SR, Bhattacharya SK, Nagesh S. Study on the prevalence of pulmonary tuberculosis among HIV positive attending HIV clinics in Eastern Nepal. SAARC J TUBER LUNG DIS HIVIAIDS 2011;8:1-8.

34. Ngowi BJ, Mfinanga SG, Bruun JN, Morkve O. Pulmonary Tuberculosis among people living with HIVIAIDS attending care and treatment in rural northern Tanzania. BMC Public Health 2008;8:341. 